\title{
Optimisation of Refrigeration System with Two-Stage and Intercooler Using Fuzzy Logic and Genetic Algorithm
}

\author{
Bayram Kılıç \\ Mehmet Akif Ersoy University, Bucak Emin Gülmez Vocational School, Burdur \\ E-mail address: bayramkilic@mehmetakif.edu.tr
}

Received date: February 2017

\begin{abstract}
Two-stage compression operation prevents excessive compressor outlet pressure and temperature and this operation provides more efficient working condition in low-temperature refrigeration applications. Vapor compression refrigeration system with two-stage and intercooler is very good solution for low-temperature refrigeration applications. In this study, refrigeration system with two-stage and intercooler were optimized using fuzzy logic and genetic algorithm. The necessary thermodynamic characteristics for optimization were estimated with Fuzzy Logic and liquid phase enthalpy, vapour phase enthalpy, liquid phase entropy, vapour phase entropy values were compared with actual values. As a result, optimum working condition of system was estimated by the Genetic Algorithm as $-6.0449^{\circ} \mathrm{C}$ for evaporator temperature, $25.0115{ }^{\circ} \mathrm{C}$ for condenser temperature and 5.9666 for COP. Morever, irreversibility values of the refrigeration system are calculated.
\end{abstract}

Keywords: Optimisation, Refrigeration System, COP, Genetic Algorithm, Fuzzy Logic

\section{Introduction}

Mohanraja et al. have been reviewed energy and exergy analysis of refrigeration, air conditioning and heat pump systems using artificial neural networks. Their study shown that ANN method has given satisfactory results for air conditioning and heat pump systems [1]. Zhao et al. have used a model-based optimization method for vapour compression refrigeration cycle. They have used modified genetic algorithm as optimization method. Modified genetic algorithm results have compared with traditional methods. As a result of study, they have shown that data obtained from their study is suitable for actual systems [2]. Sanaye and Asgari were investigated performance of the thermal modelling of gas engine driven air-to-water heat pump system with engine heat recovery heat exchangers for the heating mode of operation. In their study, artificial neural network and the multi-objective genetic algorithm optimization method were used to prediction of thermodynamic characteristics of system components. Results of study were compared with experimental data. Their results showed that acceptable for operating pressure, gas engine fuel consumption, outlet water temperature, engine rotational speed, and system primary energy ratio [3]. Kamar et al. have made to estimation cooling capacity, compressor power input and the coefficient of performance of the automotive air-conditioning system for passenger car using artificial neural networks model. They have constructed experimental system for this study. The experimental system was operated at steady-state conditions. And they have changed the compressor speed, air temperature at evaporator 
inlet, air temperature at condenser inlet and air velocity at evaporator inlet. Root mean square error (RMSE) was obtained in the range of \%0.33-0.95 and mean square error (MSE) were obtained between 1.09x105 and 9.05x105 in their study [4]. Esen and Inalli have been examined to estimation of performance of a vertical ground source heat pump system with artificial neural network and an adaptive neuro-fuzzy inference system. Esen and Inalli have compared that obtained data from artificial neural network and an adaptive neuro-fuzzy inference system. Their results showed that adaptive neuro-fuzzy inference system (ANFIS) method has given more consistent results for estimation of performance of vertical ground source heat pump system [5]. Şencan et al. have used artificial neural network method for determination of thermophysical properties of refrigerants. These properties are heat conduction coefficient, dynamic viscosity, kinematic viscosity, thermal diffusivity, density, specific heat capacity of refrigerants. They worked on five refrigerants. Five refrigerants are: R413A, R417A, R422A, R422D and R423A. As a result of their study, they have derived an equation for estimation of thermodynamic properties of the refrigerants [6].

In the literature, experimental studies on optimization of refrigeration system with two-stage and intercooler are very limited. In this study, refrigeration system with two-stage and intercooler were optimized using fuzzy logic and genetic algorithm.

\section{Modelling, Solkane Program, Fuzzy Logic and Genetic Algorithm}

\subsection{Solkane Program}

The necessary thermodynamic properties for optimization were calculated by Solkane program. Solkane program is a powerful calculation program for thermodynamic properties. It calculates the thermodynamic substance data and transport properties of all refrigerants and some CFCs. It contains modules for the calculation of a total of 7 different ones and two-step cycle processes and for dimensioning of a refrigerant's pipe lines. Besides, Solkane program contains 5 different cooling cycle and 2 different Rankine cycle in the program structure [10].

\subsection{Fuzzy Logic}

Fuzzy Logic can be described as expression of uncertainty and solid mathematical a scheme that established to work with uncertainty. As is known in statistics and probability theory, works with certainty not with uncertainty. But, environment in which people live is filled with more uncertainty. So, should work with uncertainty for in order to understand mankind's the ability to draw conclusions.

In the logic of Aristotle are black or white. In the real world, you cannot find the full black or full white. Fuzzy logic almost exclusively works with grey in accordance with the real life. There are black or white in extreme cases. Complex systems are difficult controlled and modeling with classical logic methods. Fuzzy logic that people are relieved of the obligation and provide the ability to define a more qualitative.

Fuzzy Logic is used for applications such as cameras, washing machines, air conditioning and automatic transmission lines. Furthermore, it is used in space exploration and aerospace industries. A fuzzy logic model consists of four components. These components are fuzzifiers, the inference engine, the defuzzifier and a fuzzy rule base (Figure 1). 
In the fuzzy logic, "and method", "or method", "implication", "aggregation" ve "defuzzification" are used as "min", "max", "min", "max", "centroid". The Mamdani method was applied. The fitness function of all variables in fuzzy logic is chosen as "trimf".

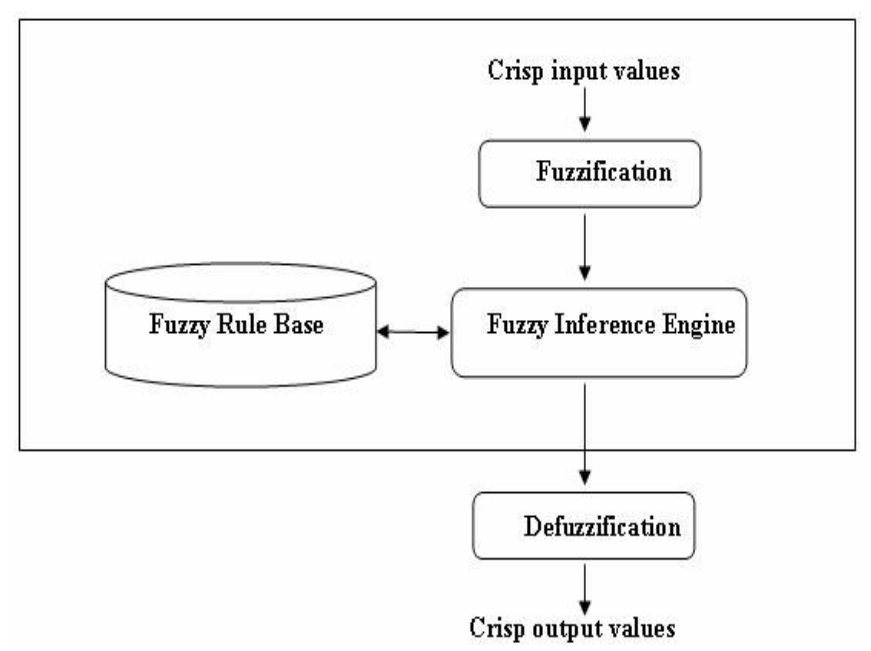

Fig.1. Basic flow chart of fuzzy logic [9]

Input values in the fuzzifier are fuzzified into linguistic values to be associated to the input linguistic variables. After fuzzification, the inference engine refers to the fuzzy rule base containing fuzzy IFTHEN rules to derive the linguistic values for the intermediate and output linguistic variables. The defuzzifier produces the final values from the output values and these output values are available.

\subsection{Genetic Algorithm}

The genetic algorithm is a method for solving both constrained and unconstrained optimization problems that is based on natural selection, the process that drives biological evolution. The genetic algorithm repeatedly modifies a population of individual solutions. At each step, the genetic algorithm selects individuals at random from the current population to be parents and uses them to produce the children for the next generation. Over successive generations, the population "evolves" toward an optimal solution [9-]. Basic flow chart of Genetic Algorithm was given in Figure 2.

Genetic algorithm procedure is as follows;

Step 1. Start: Initial population is created after $\mathrm{N}$ chromosomes with $\mathrm{m}$ pieces individuals are produced as randomly for to solve of the problem. Or, the initial population may also be created from specific individuals.

Step 2. Fitness: Objective function is calculated for each individual in the population.

Step 3. New population: Following steps are repeated until the formation of a new population;

a) Selection: According to the fitness value of the objective function selected individuals from the population are thrown into the match's pool for crossover. 
b) Crossover: Individuals that selected from matching pool are crossed among themselves until crossover rate child individual.

c) Mutation: Any chromosomes of selected individual or individuals from in the population are reset and instead a new value is assigned.

d) Admission: The first population, children and mutated individuals constitute a new population.

Step 4. Replacement: Consisting new population are sorted according to fitness value and until the number of individuals in the population is assigned as the new initial population.

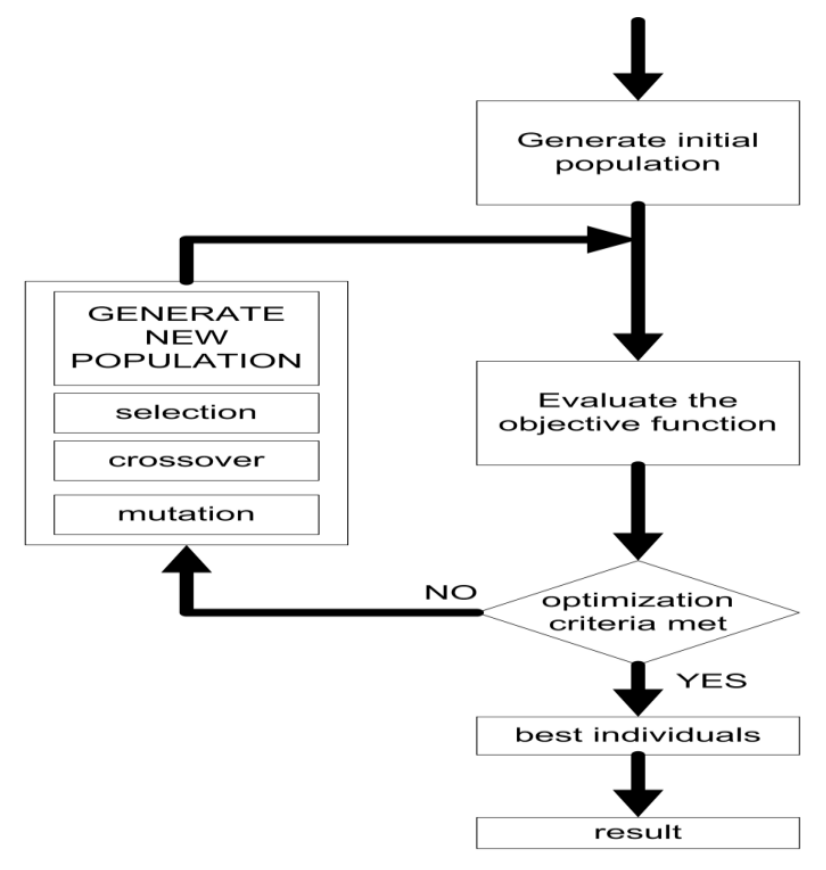

Fig.2. Basic flow chart of Genetic Algorithm [7]

Step 5. Test: If the program finishing requirement is happening, the program is stopped.

Step 6. Cycle: Otherwise, the program go back to step 2.

\section{Results and discussion}

In this study, refrigeration system with two-stage and intercooler were optimized by using fuzzy logic and genetic algorithm. The required thermodynamic characteristics for optimization were estimated with Fuzzy Logic and these values were compared with actual values.

Input- output parameter used in fuzzy logic was given in Figure 3. MATLAB Fuzzy Logic Toolbox is used for estimation for thermodynamic properties in the study. Mamdani type fuzzy inference system (FIS) was used. Type of membership function is trimf. 40 piece training values and 15 piece test values have been used in fuzzy logic. 4 input values and 14 output values in system have taken into consideration in fuzzy logic. Input values are evaporator temperature, evaporator pressure, condenser temperature and condenser pressure. Evaporator temperature is in the range of $-6{ }^{\circ} \mathrm{C}$ to -24 
${ }^{\circ} \mathrm{C}$, the condenser temperature is in the range from $25{ }^{\circ} \mathrm{C}$ to $40{ }^{\circ} \mathrm{C}$. Output values are enthalpy values, entropy values, the mass flow rate, electric charge of the high and low pressure compressors for all in each point of the system. Some of rules used in fuzzy logic technic are given in Figure 4.

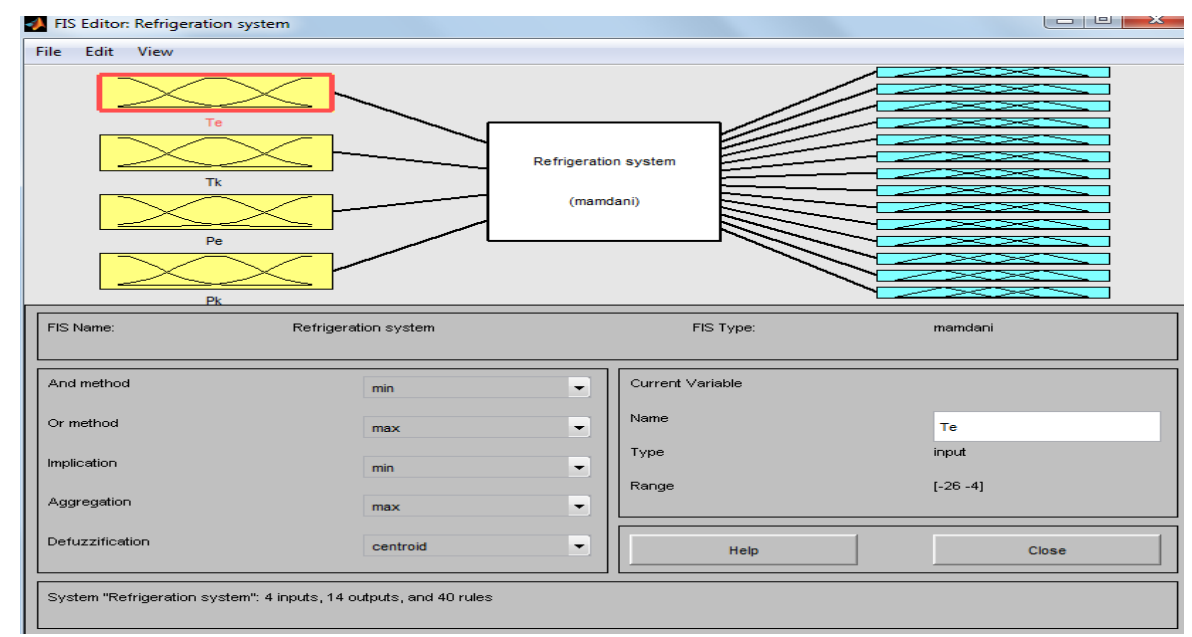

Fig.3. Input-output values for refrigeration system in fuzzy logic

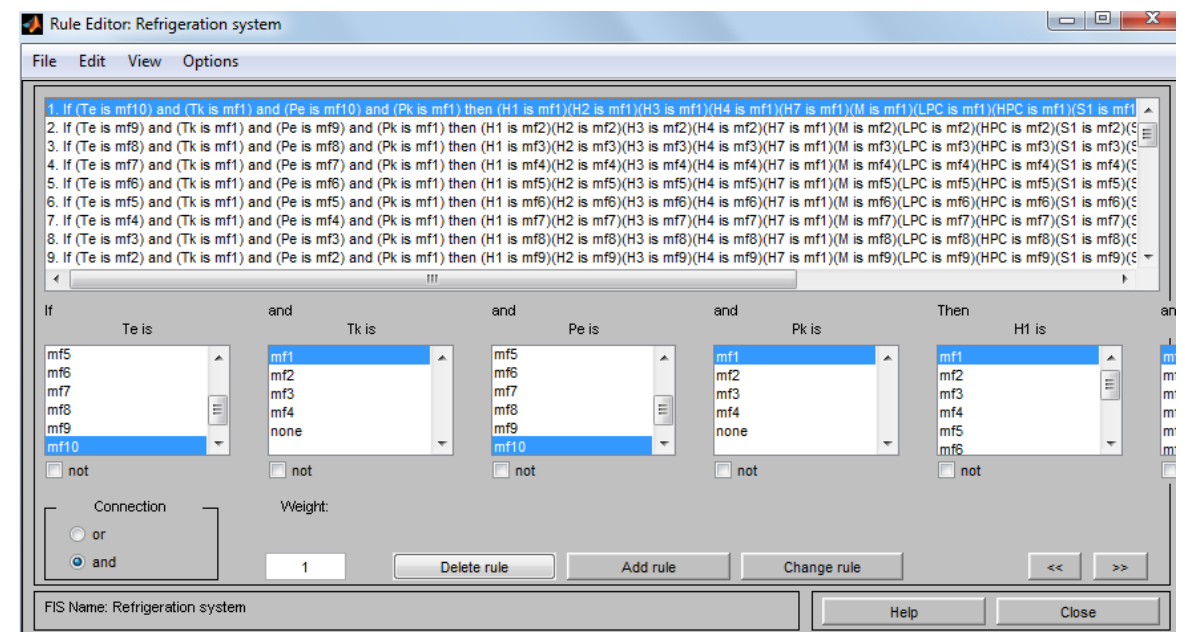

Fig.4. Rules of fuzzy logic 


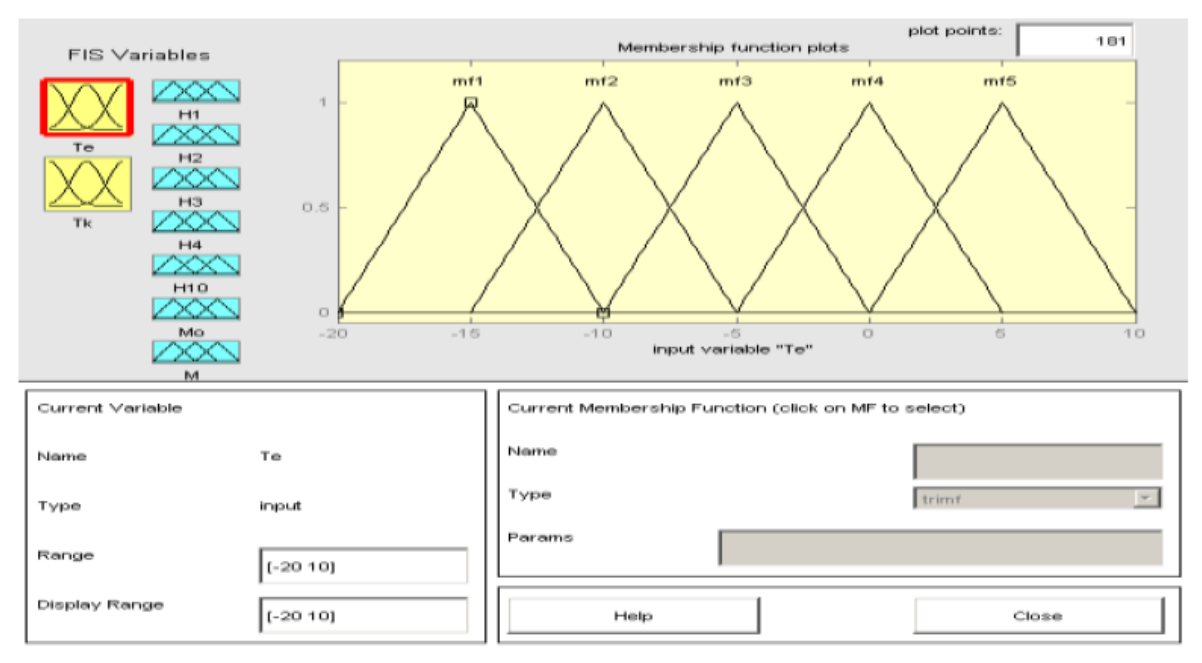

Fig.5. Membership Function (for evaporator temperature)

Comparison of actual high pressure compressor outlet enthalpy values and estimated enthalpy values was given in Figure 6 as exemplarily. Comparison of actual high pressure compressor outlet entropy values and estimated entropy values was given in Figure 7 as exemplarily.

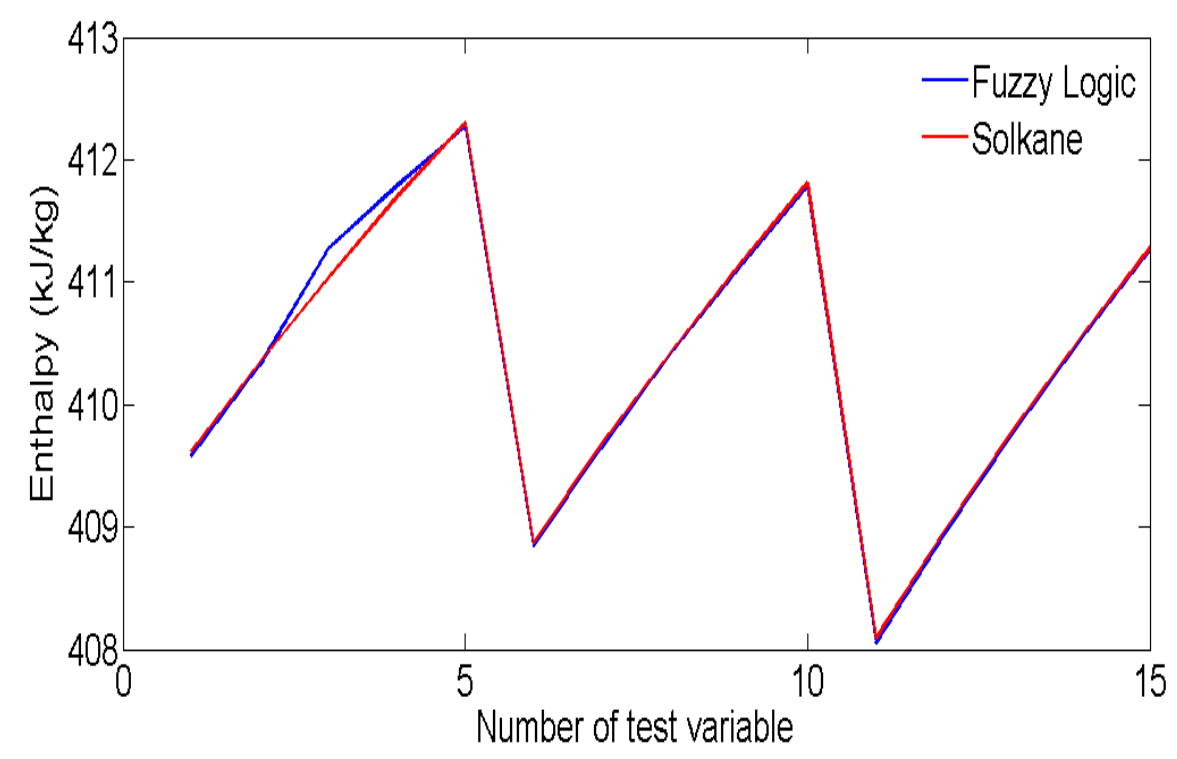

Fig.6. Comparison of actual high pressure compressor outlet enthalpy values and estimated enthalpy values 


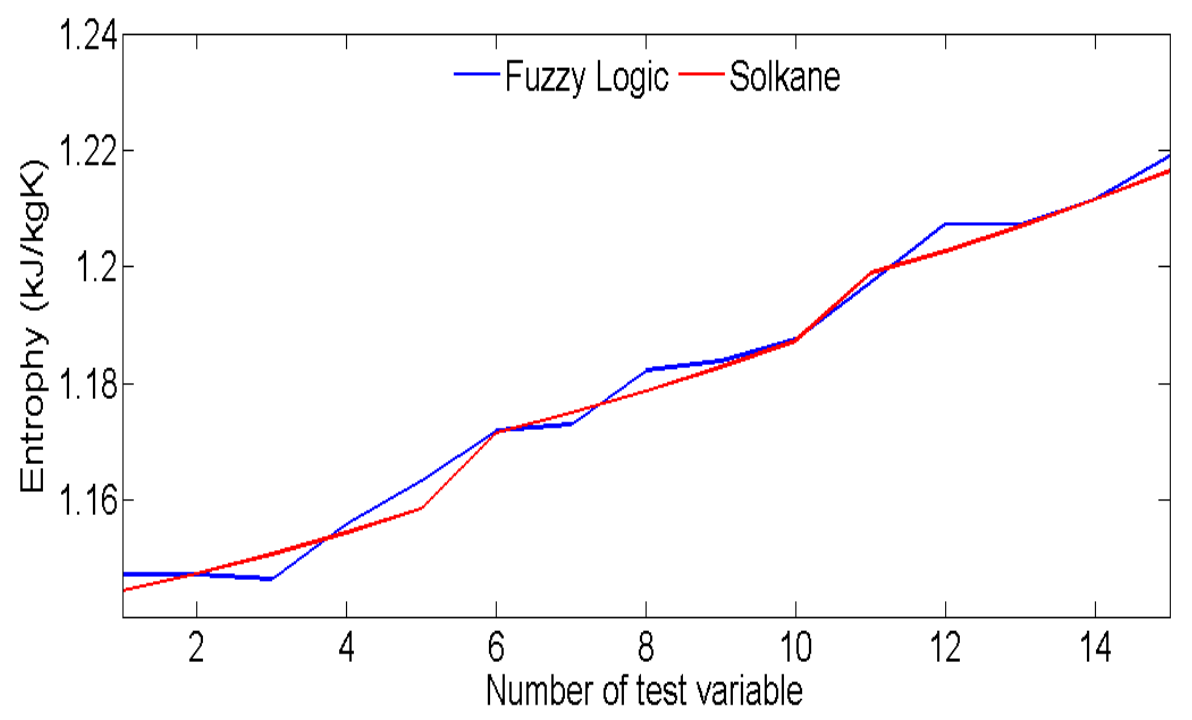

Fig.7. Comparison of actual high pressure compressor outlet entropy values and estimated entropy values

In Table 1, average absolute relative error values related to the thermodynamic values are given. As can be seen from Table 1, fuzzy logic technic has provided a good estimate values.

Table 1. Average absolute relative error values.

\begin{tabular}{|r|c|}
\hline & Average Absolute Relative Error \\
\hline Evaporator output enthalpy & 0 \\
\hline Low Pressure Compressor output enthalpy & $1.13 \times 10^{-4}$ \\
\hline High Pressure Compressor input enthalpy & $8.27 \times 10^{-4}$ \\
\hline Condenser input enthalpy & $4.07 \times 10^{-5}$ \\
\hline Evaporator input enthalpy & $2.2 \times 10^{-3}$ \\
\hline Evaporator output entropy & $1.78 \times 10^{-5}$ \\
\hline Low Pressure Compressor output entropy & $6 \times 10^{-9}$ \\
\hline High Pressure Compressor input entropy & 1.75 \\
\hline Condenser input entropy & 1.77 \\
\hline Condenser output entropy & 1.75 \\
\hline Evaporator input entropy & 1.76 \\
\hline Electric charge of the Low Pressure Compressor & 1.15 \\
\hline Electric charge of the High Pressure Compressor & $1.15 \times 10^{-5}$ \\
\hline
\end{tabular}


Table 2. Comparison between actual enthalpy values and enthalpy values estimated from Fuzzy Logic for R-134a

\begin{tabular}{|c|c|c|c|c|c|c|c|}
\hline Temperature & Pressure & \multicolumn{3}{|c|}{ Liquid Phase Enthalpy } & \multicolumn{3}{|c|}{ Vapour Phase Enthalpy } \\
\hline $\begin{array}{c}\mathbf{T} \\
\left({ }^{\circ} \mathrm{C}\right)\end{array}$ & $\begin{array}{c}\mathbf{P} \\
\text { (bar) }\end{array}$ & $\begin{array}{l}\text { Actual } \\
\text { Values } \\
(\mathbf{k J} / \mathbf{k g})\end{array}$ & $\begin{array}{c}\text { Estimated } \\
\text { values with } \\
\text { Fuzzy Logic } \\
(\mathbf{k J} / \mathbf{k g K})\end{array}$ & Error & $\begin{array}{l}\text { Actual } \\
\text { Values } \\
(\mathbf{k J} / \mathbf{k g})\end{array}$ & $\begin{array}{c}\text { Estimated } \\
\text { values with } \\
\text { Fuzzy Logic } \\
(\mathbf{k J} / \mathbf{k g K})\end{array}$ & Error \\
\hline-24 & 1.11 & 168.41 & 168.42 & 0.01 & 384.04 & 384.04 & 0 \\
\hline-23 & 1.16 & 169.69 & 169.7 & 0.01 & 384.66 & 384.65 & 0.01 \\
\hline-22 & 1.22 & 170.98 & 170.98 & 0 & 385.28 & 385.28 & 0 \\
\hline-21 & 1.27 & 172.27 & 172.28 & 0.01 & 385.89 & 385.89 & 0 \\
\hline-20 & 1.33 & 173.56 & 173.55 & 0.01 & 386.51 & 386.51 & 0 \\
\hline-19 & 1.39 & 174.85 & 174.86 & 0.01 & 387.12 & 387.12 & 0 \\
\hline-18 & 1.45 & 176.15 & 176.16 & 0.01 & 387.73 & 387.73 & 0 \\
\hline-17 & 1.51 & 177.45 & 177.45 & 0 & 388.34 & 388.35 & 0.01 \\
\hline-16 & 1.57 & 178.75 & 178.76 & 0.01 & 388.95 & 388.95 & 0 \\
\hline-15 & 1.64 & 180.06 & 180.07 & 0.01 & 389.56 & 389.56 & 0 \\
\hline-14 & 1.71 & 181.36 & 181.36 & 0 & 390.17 & 390.17 & 0 \\
\hline-13 & 1.78 & 182.68 & 182.68 & 0 & 390.77 & 390.77 & 0 \\
\hline-12 & 1.85 & 183.99 & 183.99 & 0 & 391.38 & 391.38 & 0 \\
\hline-11 & 1.93 & 185.31 & 185.31 & 0 & 391.98 & 391.98 & 0 \\
\hline-10 & 2.01 & 186.63 & 186.62 & 0.01 & 392.58 & 392.58 & 0 \\
\hline-9 & 2.09 & 187.95 & 187.96 & 0.01 & 393.18 & 393.18 & 0 \\
\hline-8 & 2.17 & 189.28 & 189.28 & 0 & 393.78 & 393.78 & 0 \\
\hline-7 & 2.25 & 190.61 & 190.61 & 0 & 394.37 & 394.37 & 0 \\
\hline-6 & 2.34 & 191.94 & 191.94 & 0 & 394.97 & 394.97 & 0 \\
\hline-5 & 2.43 & 193.27 & 193.28 & 0.01 & 395.56 & 395.55 & 0.01 \\
\hline-4 & 2.53 & 194.61 & 194.61 & 0 & 396.15 & 396.15 & 0 \\
\hline-3 & 2.62 & 195.95 & 195.96 & 0.01 & 396.74 & 396.74 & 0 \\
\hline-2 & 2.72 & 197.3 & 197.3 & 0 & 397.32 & 397.32 & 0 \\
\hline-1 & 2.82 & 198.64 & 198.66 & 0.02 & 397.91 & 397.9 & 0.01 \\
\hline 0 & 2.93 & 200 & 200 & 0 & 398.49 & 398.49 & 0 \\
\hline
\end{tabular}


Table 3. Comparison between actual entropy values and entropy values estimated from Fuzzy Logic for R-134a.

\begin{tabular}{|c|c|c|c|c|c|c|c|}
\hline Temperature & Pressure & \multicolumn{3}{|c|}{ Liquid Phase Entropy } & \multicolumn{3}{|c|}{ Vapour Phase Entropy } \\
\hline $\begin{array}{c}\mathbf{T} \\
\left({ }^{\circ} \mathbf{C}\right)\end{array}$ & $\begin{array}{c}\mathbf{P} \\
\text { (bar) }\end{array}$ & $\begin{array}{c}\text { Actual } \\
\text { Values } \\
\text { (kJ/kgK) }\end{array}$ & $\begin{array}{c}\text { Estimated } \\
\text { values with } \\
\text { Fuzzy Logic } \\
(\mathrm{kJ} / \mathrm{kgK})\end{array}$ & Error & $\begin{array}{c}\text { Actual } \\
\text { Values } \\
(\mathbf{k J} / \mathbf{k g K})\end{array}$ & $\begin{array}{c}\text { Estimated } \\
\text { values with } \\
\text { Fuzzy Logic } \\
(\mathbf{k J} / \mathbf{k g K})\end{array}$ & Error \\
\hline-24 & 1.11 & 0.8793 & 0.87931 & $1.10^{-5}$ & 1.745 & 1.745 & 0 \\
\hline-23 & 1.16 & 0.8845 & 0.88443 & $7.10^{-5}$ & 1.744 & 1.744 & 0 \\
\hline-22 & 1.22 & 0.8896 & 0.88965 & $5.10^{-5}$ & 1.7431 & 1.7431 & 0 \\
\hline-21 & 1.27 & 0.8948 & 0.89473 & $7.10^{-5}$ & 1.7421 & 1.7421 & 0 \\
\hline-20 & 1.33 & 0.8999 & 0.89987 & $3.10^{-5}$ & 1.7412 & 1.7411 & $1.10^{-4}$ \\
\hline-19 & 1.39 & 0.905 & 0.90502 & $2.10^{-5}$ & 1.7403 & 1.7403 & 0 \\
\hline-18 & 1.45 & 0.9101 & 0.91007 & 3. $10^{-5}$ & 1.7394 & 1.7394 & 0 \\
\hline-17 & 1.51 & 0.9152 & 0.91516 & $4.10^{-5}$ & 1.7385 & 1.7386 & $1.10^{-4}$ \\
\hline-16 & 1.57 & 0.9203 & 0.92034 & $4.10^{-5}$ & 1.7377 & 1.7378 & $1.10^{-4}$ \\
\hline-15 & 1.64 & 0.9254 & 0.92535 & $5.10^{-5}$ & 1.7369 & 1.7369 & 0 \\
\hline-14 & 1.71 & 0.9304 & 0.93044 & $4.10^{-5}$ & 1.7361 & 1.7361 & 0 \\
\hline-13 & 1.78 & 0.9355 & 0.93543 & $7.10^{-5}$ & 1.7353 & 1.7354 & $1.10^{-4}$ \\
\hline-12 & 1.85 & 0.9405 & 0.94049 & $1.10^{-5}$ & 1.7346 & 1.7346 & 0 \\
\hline-11 & 1.93 & 0.9455 & 0.94548 & $2.10^{-5}$ & 1.7338 & 1.7338 & 0 \\
\hline-10 & 2.01 & 0.9505 & 0.95046 & $4.10^{-5}$ & 1.7331 & 1.7331 & 0 \\
\hline-9 & 2.09 & 0.9555 & 0.95547 & $3.10^{-5}$ & 1.7324 & 1.7324 & 0 \\
\hline-8 & 2.17 & 0.9605 & 0.96045 & $5.10^{-5}$ & 1.7317 & 1.7316 & $1.10^{-4}$ \\
\hline-7 & 2.25 & 0.9655 & 0.96546 & $4.10^{-5}$ & 1.731 & 1.731 & 0 \\
\hline-6 & 2.34 & 0.9705 & 0.97052 & $2.10^{-5}$ & 1.7304 & 1.7304 & 0 \\
\hline-5 & 2.43 & 0.9754 & 0.97542 & $2.10^{-5}$ & 1.7297 & 1.7299 & $2.10^{-4}$ \\
\hline-4 & 2.53 & 0.9804 & 0.98043 & $3.10^{-5}$ & 1.7291 & 1.7291 & 0 \\
\hline-3 & 2.62 & 0.9853 & 0.98533 & $3.10^{-5}$ & 1.7285 & 1.7285 & 0 \\
\hline-2 & 2.72 & 0.9902 & 0.99022 & $2.10^{-5}$ & 1.7279 & 1.7279 & 0 \\
\hline-1 & 2.82 & 0.9951 & 0.99512 & $2.10^{-5}$ & 1.7273 & 1.7272 & $1.10^{-4}$ \\
\hline 0 & 2.93 & 1 & 1 & 0 & 1.7267 & 1.7266 & $1.10^{-4}$ \\
\hline
\end{tabular}


Optimum working conditions of refrigeration system with two-stage and intercooler were determined in order to obtain maximum cooling coefficient of performance (COP) by the Genetic Algorithm. The objective functions used in Genetic Algorithm are:

$$
\text { COP } P_{\text {max. }}=\frac{\text { Cooling load }}{\text { Power input }}
$$

Figure 8 shows results of genetic algorithm for the condenser temperature with COP value. Evaporator temperature is constant. Figure 9 shows results of genetic algorithm for the evaporator temperature with COP value. Condenser temperature is constant.

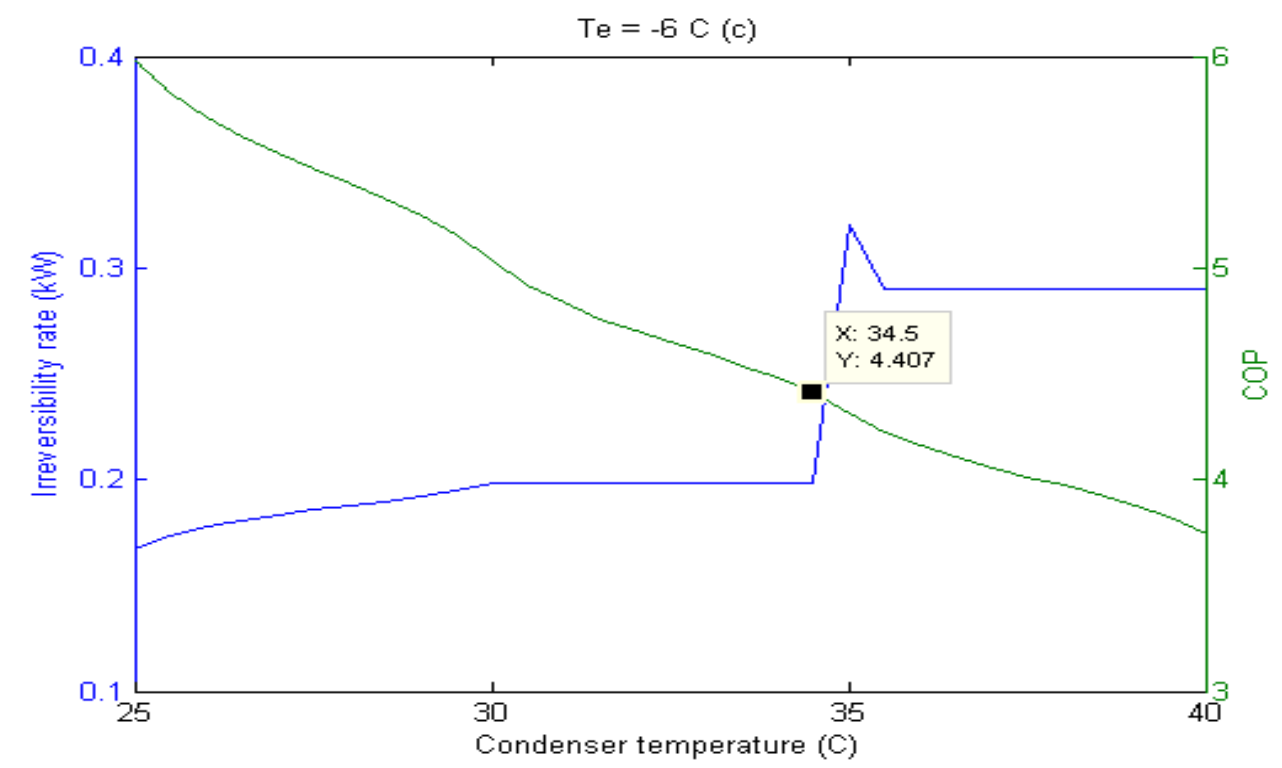

Fig.8. Genetic algorithm results for irreversibility and COP values depend on condenser temperature variation.

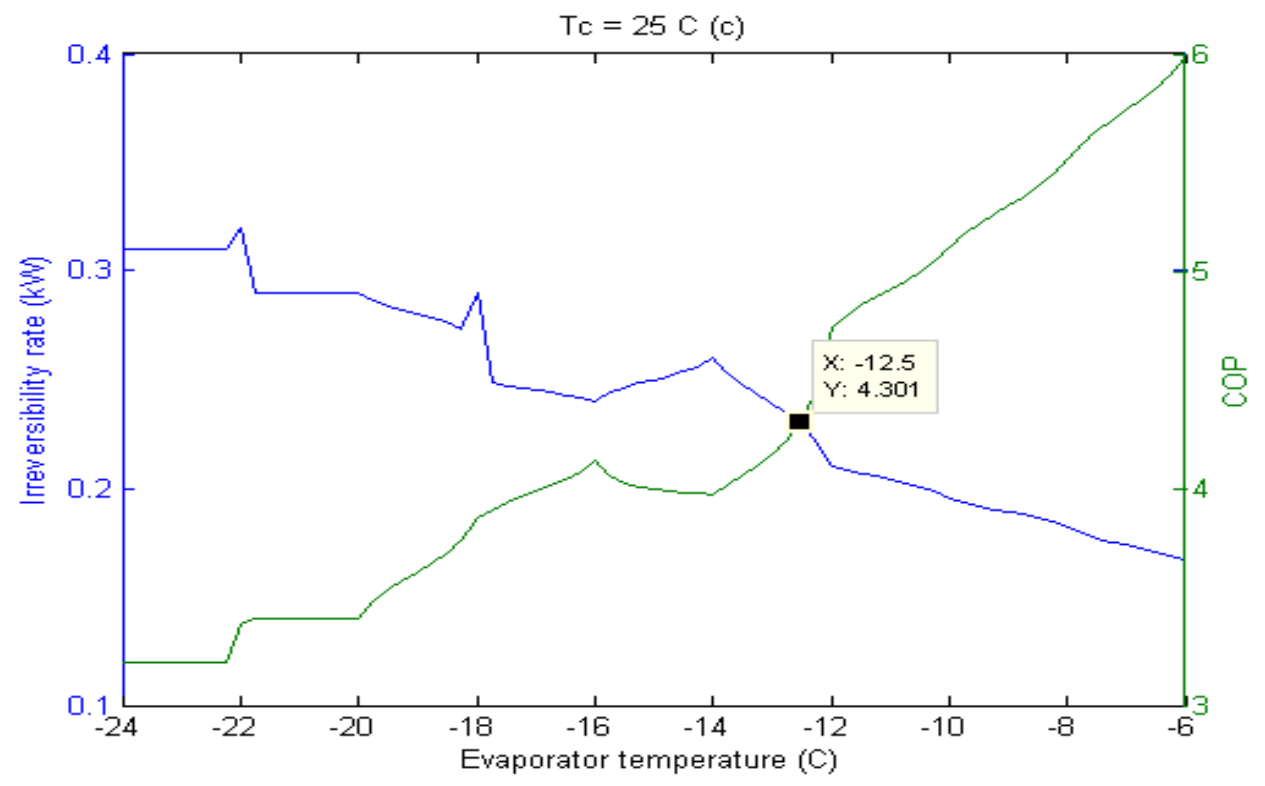

Fig.9. Genetic algorithm results for irreversibility and COP values depend on evaporator temperature variation. 
Genetic algorithm results for COP values depend on condenser and evaporator temperatures are shown in Figure 10. In this study, optimum working condition of system was estimated by the Genetic Algorithm as $-6.0449{ }^{\circ} \mathrm{C}$ for evaporator temperature, $25.0115{ }^{\circ} \mathrm{C}$ for condenser temperature and 5.9666 for COP.

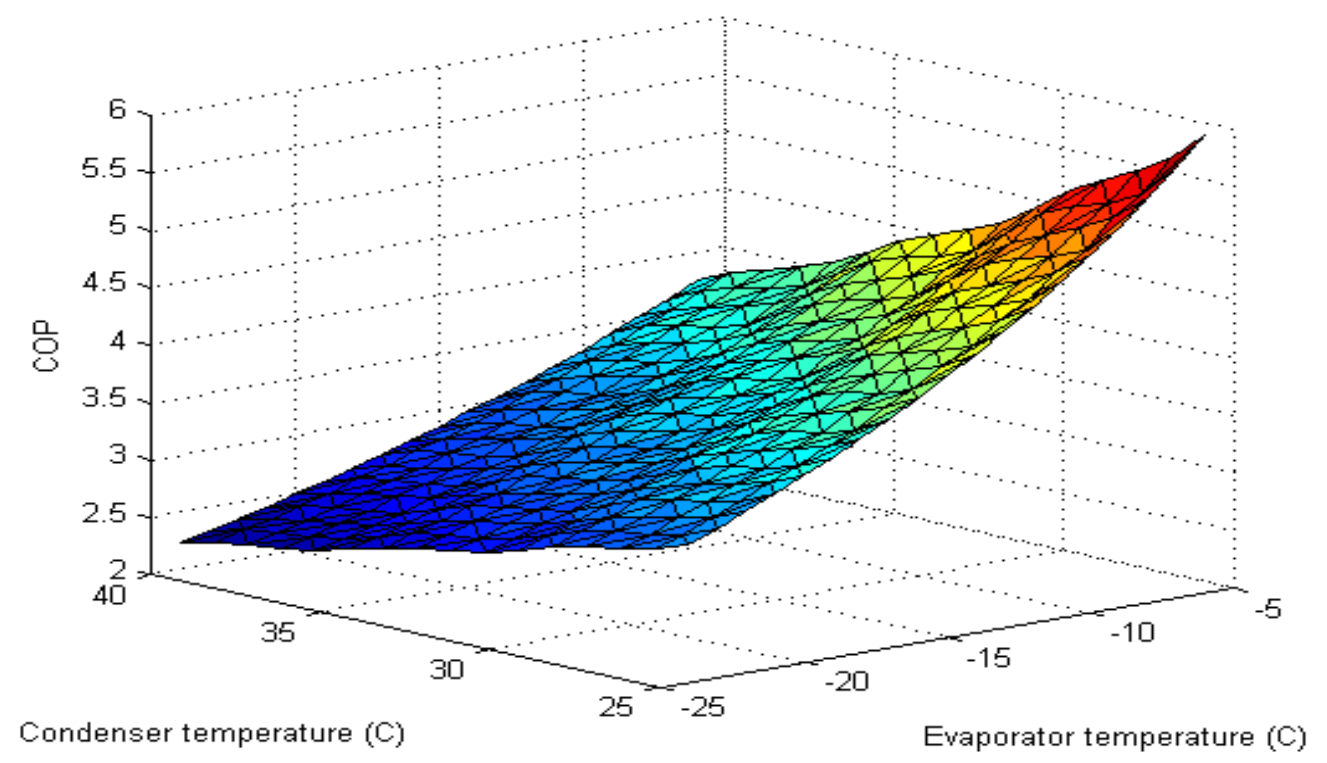

Fig.10. Genetic algorithm results for COP values.

Genetic algorithm results for irreversibility values depend on condenser and evaporator temperatures are shown in Figure 11. In this study, irreversibility rate was $0.45 \mathrm{~kW}$ as the highest value. In the Pareto analysis, optimum values of refrigeration system were forecasted by the Genetic Algorithm as 5.98 for COP, $0.167 \mathrm{~kW}$ for irreversibility rate.

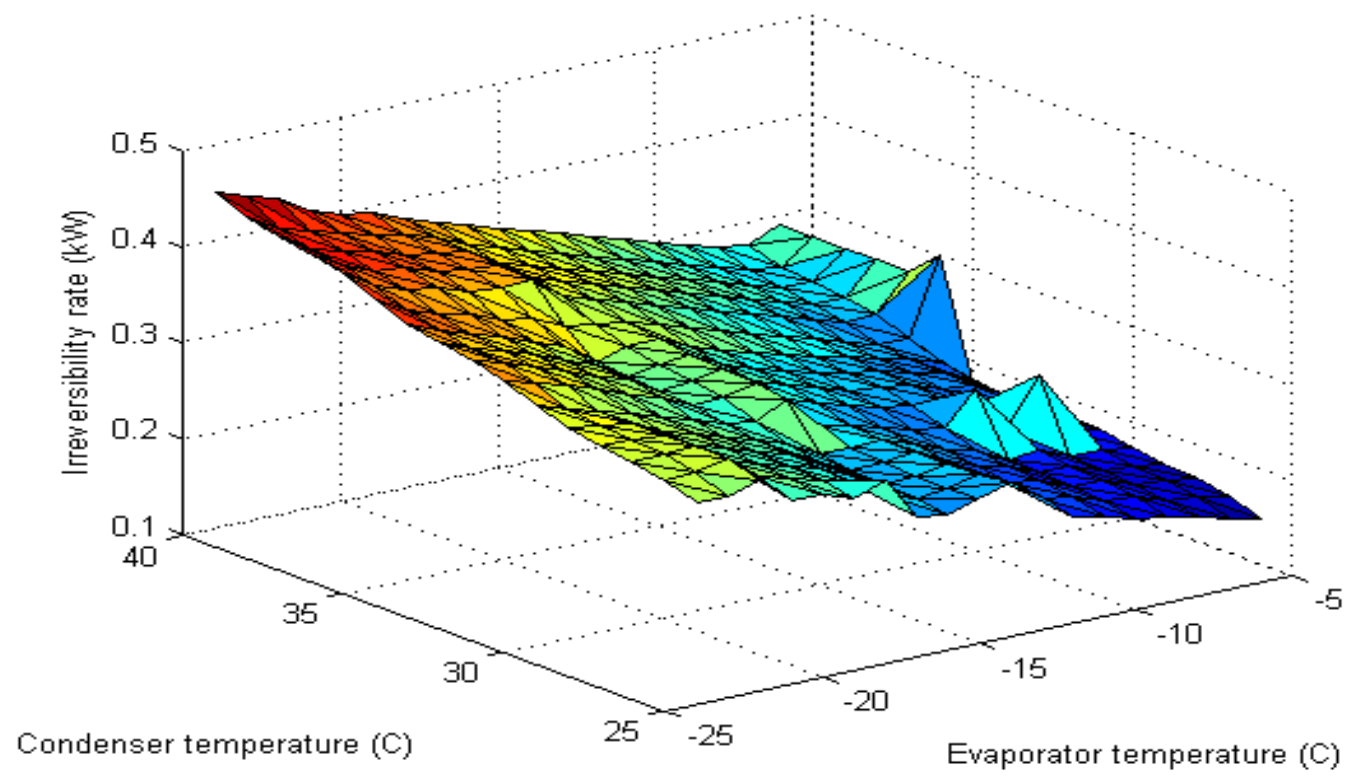

Fig.11. Genetic algorithm results for irreversibility values. 


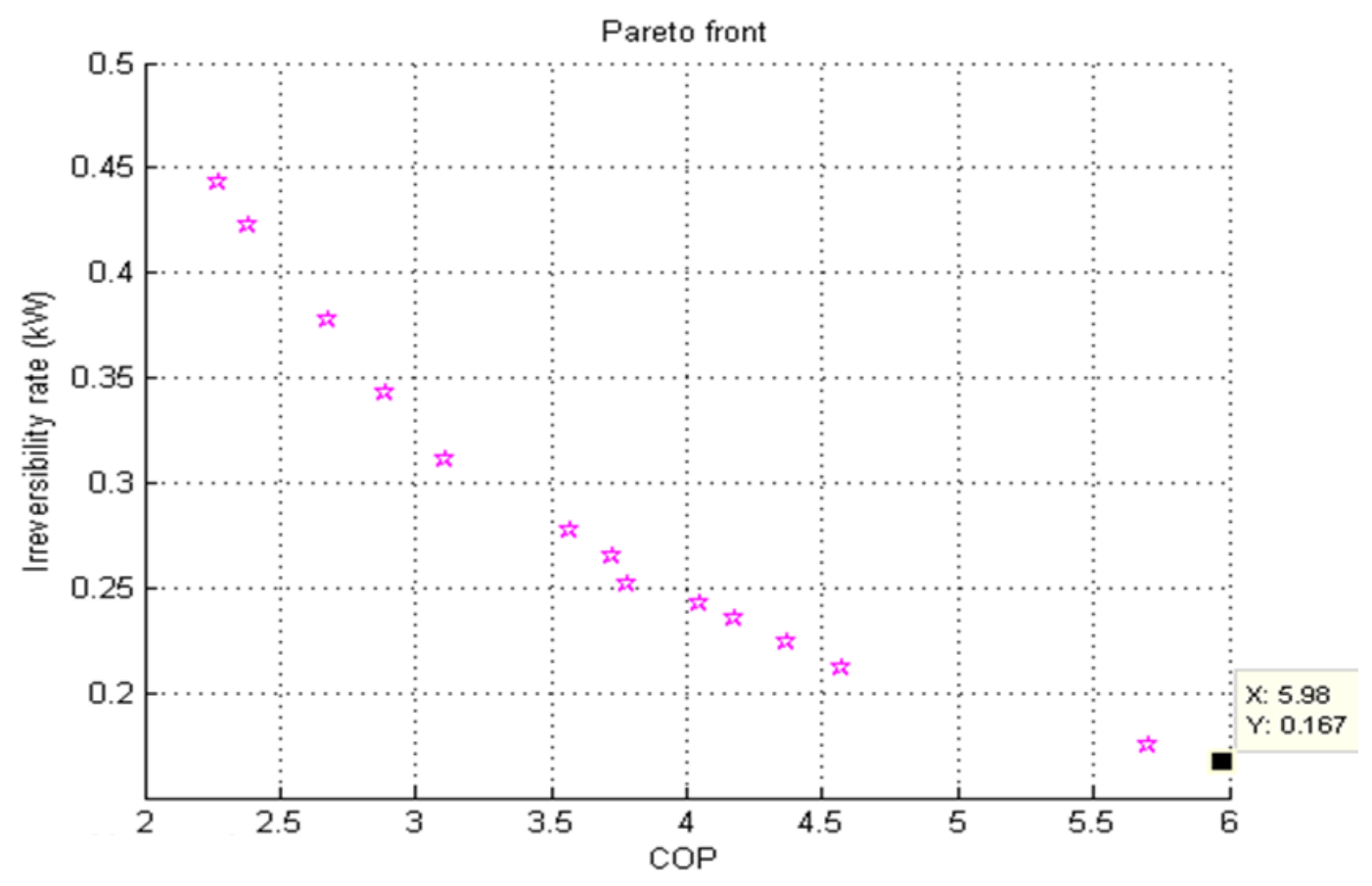

Fig.12. Pareto analysis of the refrigeration system.

\section{Conclusions}

In this study, refrigeration system with two-stage and intercooler were optimized using fuzzy logic and genetic algorithm. The necessary thermodynamic characteristics for optimization were forecasted with Fuzzy Logic and these values were compared with actual results. As results of this study, optimum working condition of refrigeration system was estimated by the Genetic Algorithm as $-6.0449{ }^{\circ} \mathrm{C}$ for evaporator temperature, $25.0115{ }^{\circ} \mathrm{C}$ for condenser temperature and 5.9666 for COP. Moreover, irreversibility values of the refrigeration system were calculated and irreversibility rate was $0.45 \mathrm{~kW}$ as the highest value. This work shows that Genetic Algorithm can use for determining optimum working conditions of the refrigeration system with two-stage and intercooler.

From the literature review aforesaid above, it is seen that basic computational intelligence techniques are used in the transcritical $\mathrm{CO}_{2}$ one-stage vapor compression cycles. However, an ANN method has not been carried out for the coefficient of performance (COP) in the transcritical $\mathrm{CO}_{2}$ one-stage vapor compression cycles yet. This paper is focused on the applicability of ANN methods for estimation the coefficient of performance (COP).

\section{References}

[1] Mohanraja, M., Jayaraj, S., Muraleedharan, C., Applications of artificial neural networks for refrigeration. Air-conditioning and heat pump systems-A review. Renewable and Sustainable Energy Reviews, 16, 1340-1358, 2012. 
[2] Zhao, L., Cai, W., Ding, X., Chang L., Model-based optimization for vapor compression refrigeration cycle. Energy, 55, 392-402, 2013.

[3] Sanaye, S., Asgari, H., Thermal modeling of gas engine driven air to water heat pump systems in heating mode using genetic algorithm and Artificial Neural Network methods. International Journal of Refrigeration, 36, 2262-2277, 2012.

[4] Kamar, H., Ahmad, R., Kamsah, N., Mustafa, A., Artificial neural networks for automotive airconditioning systems performance prediction. Applied Thermal Engineering, 50, 63-70, 2013.

[5] Esen, H., Inalli, M., ANN and ANFIS models for performance evaluation of a vertical ground source heat pump system. Expert Systems with Applications, 37, 8134-8147, 2010.

[6] Sencan, A., Köse, I., Selbas, R., Prediction of thermophysical properties of mixed refrigerants using artificial neural network. Heat Mass Transfer, 47, 1553-1560, 2011.

[7] Chakraborty, D., Sharma, C., Abhishek, B., Malakar, T., Distribution System Load Flow Solution Using Genetic Algorithm. ICPS'09 International Conference on power systems, 1-6, 2009.

[8] Özdemir, A., Lim, Y., Singh, C., Post-outage reactive power flow calculations by genetic algorithms: constrained optimization approach. IEEE Transactions on Power Systems, 20, 12661272, 2005.

[9] Sencan, A., Kilic, B., K1lic, U., Optimization of heat pump using fuzzy logic and genetic algorithm. Heat Mass Transfer, 47, 1553-1560, 2011.

[10] Kilıc, B., Alternative Approach For Thermal Analysis Of Transcritical $\mathrm{Co}_{2}$ One-Stage Vapor Compression Cycles. International Journal of Engineering \& Applied Sciences (IJEAS), 8, 1-6,2016. 